\title{
WRF model sensitivity for simulating intense western disturbances over North West India
}

\author{
Rupesh Patil $^{1,2} \cdot$ P. Pradeep Kumar ${ }^{1}$
}

Received: 13 April 2016/Accepted: 22 April 2016/Published online: 2 May 2016

(C) Springer International Publishing Switzerland 2016

\begin{abstract}
During winter season, large amount of precipitation is received in the Northwestern part of India due to eastward moving low pressure synoptic weather systems called western disturbances (WDs). These WD's disturbs the life in Northern India with heavy precipitation, cold wave and fog. The objective of the present study is to examine model sensitivity of different physical parameterization schemes incorporated in the weather research and forecasting model and to identify a combination of the best physics options suited for this region during the passage of a western disturbance. Four cases of intense western disturbances 13-17 January 2002 (case-1), 5-8 February 2002 (case-2), 16-19 January 2013 (case-3) and 4-7 February 2013 (case-4) which affected the northwest India has been simulated with different physics configurations in the model. The model simulation from different physics configurations are validated with the observational datasets and error statistics are presented. It is found that, the performance of the combination of National Severe Storms Laboratory one moment, Kain-Fritsch, Yonsei University, rapid radiative transfer model and Dudhia schemes as a microphysics, cumulus, planetary boundary layer, longwave radiation and shortwave radiation parameterization schemes respectively gives a better simulation of the weather during WD's over this region. It is found that, in all WD cases intensity and movement of the precipitation, circulation and low pressure area (geopotential height) over the region is well predicted by the model.
\end{abstract}

\section{P. Pradeep Kumar}

ppk@unipune.ac.in

1 Department of Atmospheric and Space Sciences, Savitribai Phule Pune University, Pune 411007, India

2 Abasaheb Garware College, Karve Road, Pune 411004, India
Keywords Western disturbance - WRF . Parameterization $\cdot$ Microphysics

\section{Introduction}

The winter season over India is characterized by dominating influence of cool continental air of low humidity and is therefore the period of generally cool and dry weather over most of the country (Pant and Rupa Kumar 1997). This fine weather is occasionally interrupted by the arrival of low pressure waves or weak depressions from the far west, these disturbances appear as troughs or low pressure areas at the surface or as cyclonic circulation in the upper air in the regime of westerly winds north of the sub-tropical high pressure belt (Dutta and Gupta 1967; Singh 1979; Singh et al. 1981). These migratory systems originate at frequent intervals in the Mediterranean Sea and sometimes as far west as the Atlantic ocean and there after traveling eastwards across Iraq, Iran, Afghanistan and Pakistan, they enter north India and move away further eastwards giving rise to extended cloudiness, precipitation and cold wind over northwest and north India (Rao and Srinivasan 1969). These disturbances are called western disturbances (WD) as it travels from west to east and it is also defined as an eastward moving extra-tropical upper air trough in the subtropical westerly often extending down to the lower atmospheric level of the north Indian latitudes during the winter months (Pisharoty and Desai 1956).

The arrival of western disturbance throws the life out of gear in Northwest India, causing heavy precipitation followed by chill. Therefore, forecasting the intensity of western disturbance is useful for disaster mitigation (Dimri et al. 2004). In addition to complex orography, paucity of data has made numerical weather prediction very 
Table 1 List of episode selection

\begin{tabular}{lll}
\hline WD case & Period & References \\
\hline 1 & 13-17 January 2002 & Hatwar et al. (2005) \\
2 & 5-8 February 2002 & Hatwar et al. (2005) \\
3 & 16-19 January 2013 & Medha et al. (2014) \\
4 & 4-7 February 2013 & Medha et al. (2014) \\
\hline
\end{tabular}

challenging over the region (Hatwar et al. 2005). Studies on Western Disturbances over North West India using numerical models are limited. Azadi et al. (2001) used NCAR high resolution mesoscale model to simulate active western disturbance during 1997. Dimri et al. (2004) used a mesoscale MM5 model to simulate heavy precipitation associated with an intense WD over Western Himalayas during 21-25 January 1999 when a WD affected NW India. Hatwar et al. (2005) and Dimri and Mohanty (2009) carried out prediction of western disturbance and associated weather systems over Western Himalayas using the IMD's operational limited area analysis and forecast system and MM5 model respectively.

The model used in this study is the Weather Research and Forecasting (WRF) model (Version v3.5.1) which uses the Eulerian mass coordinate and is referred to as the Advanced Research WRF (ARW). The WRF physics options have a range of physical parameterization configurations which can be used for simulation. Thus, one of the essential steps in the simulation is to choose the most appropriate combination of physics options (Optimal setup) for the region and time period under consideration. Previous studies by William and James (2006), Borge et al. (2008), Krieger et al. (2009), Flaounas et al. (2010), Kim and Wang (2011), Raju et al. (2011), Crétat et al. (2012) and others have showed that, the model forecast is sensitive to choice of physical parameterization schemes. Though previous studies have attempted to determine the sensitivity of the model and best physics options over many different regions, their conclusions may not be necessarily applicable to this region due to its different geographical features (Krieger et al. 2009). Thus, the purpose of this paper is to examine model sensitivity and identify best physics options suited for this region during the Western Disturbance. Dimri and Chevuturi (2014) have studied model sensitivity for WDs with the old version (3.0) of WRF model using five different cloud microphysics schemes. Two intense cases of WDs during the period 13-17 January 2002 (case-1)and 05-08 February 2002 (case-2) have been investigated by Hatwar et al. (2005) and Dimri and Chevuturi (2014). In addition, two more cases of WDs that affected northwest India during period of 16-19 January 2013(case-3) and 4-7 February 2013 (case 4) (see Table 1) which have occurred after a decade have been selected for the present study. During these cases of WDs, heavy precipitation has been reported from the many stations in Northern India and the Western Himalayan region. The synoptic situations associated with Case-3 and Case-4 has been discussed by Medha et al. (2014).

Five experiments have been carried out using the different Micro Physics (MP) schemes while keeping the other parameterization schemes fixed (see Tables 2, 3a). In the present study, three nested domains of resolutions 81 , 27 and $9 \mathrm{~km}$ with five different model configurations were simulated for all four WDs. Sensitivity and error statistics of three important parameters have been studied to examine model sensitivity and identify best physics options suited for simulating the weather system over this region during WD.

Table 2 Description of the model configuration used

\begin{tabular}{ll}
\hline Model version & 3.5 .1 \\
Map projection & Mercator \\
Central point of the domain & $34.7179^{\circ} \mathrm{N}, 72.597^{\circ} \mathrm{W}$ \\
Number of horizontal grid points & 102,100 grid points for $x, y$ respectively \\
Horizontal grid distance $(\mathrm{km})$ & $81,27,9$ \\
Horizontal grid system & Arakawa C straggering \\
Time integration scheme & Runge-Kutta 3rd order \\
Micro physics (MP) schemes tested & WRF single-moment 3-class (WSM3) (Hong et al. 2004) \\
& WRF single-moment 5-class scheme (WSM5) (Hong et al. 2004) \\
& Eta microphysics (Eta) [Rogers et al. (2001, web doc)] \\
& SBU-YLin (Lin and Colle 2011) \\
Cumulus parameterization (CP) & NSSL 1-momlfo (Gilmore et al. 2004) \\
Planetary boundary layer (PBL) & Kain-Fritsch (KF) (Kain 2004) \\
Longwave radiation scheme (LR) & Yonsei University (YSU) (Hong and Lim 2006) \\
Shortwave radiation (SR) & Rapid radiative transfer model (RRTM) (Mlawer et al. 1997) \\
\hline
\end{tabular}


Table 3 Microphysics schemes used with (a) combination of other parameterization schemes in 1-5 experiments and (b) summary

\begin{tabular}{|c|c|c|c|c|c|c|}
\hline Experiment & MP & $\mathrm{CP}$ & PBL & LR & & SR \\
\hline \multicolumn{7}{|l|}{ (a) } \\
\hline 1 & WSM3 & KF & YSU & RRTM & & Dudhia \\
\hline 2 & WSM5 & $\mathrm{KF}$ & YSU & RRTM & & Dudhia \\
\hline 3 & Eta & KF & YSU & RRTM & & Dudhia \\
\hline 4 & SBU-YLin & KF & YSU & RRTM & & Dudhia \\
\hline 5 & NSSL1-momlfo & KF & YSU & RRTM & & Dudhia \\
\hline MP schemes & \multicolumn{2}{|l|}{ References } & \multicolumn{2}{|c|}{ Mass variables } & \multicolumn{2}{|c|}{ Scheme added } \\
\hline \multicolumn{7}{|l|}{ (b) } \\
\hline WSM3 & \multicolumn{2}{|c|}{ Hong et al. (2004) } & \multicolumn{2}{|c|}{ Qc Qr } & \multicolumn{2}{|l|}{2004} \\
\hline WSM5 & \multicolumn{2}{|c|}{ Hong et al. (2004) } & \multicolumn{2}{|c|}{ Qc Qr Qi Qs } & \multicolumn{2}{|l|}{2004} \\
\hline Eta (Ferrier) & \multicolumn{2}{|c|}{ Rogers et al. (2001, web doc) } & \multicolumn{2}{|c|}{ Qc Qr Qs $(Q t *)$} & \multicolumn{2}{|l|}{2000} \\
\hline SBU-YLin & \multicolumn{2}{|c|}{ Lin and Colle (2011) } & \multicolumn{2}{|c|}{ Qc Qr Qi Qs } & \multicolumn{2}{|l|}{2011} \\
\hline NSSL 1-momlfo & \multicolumn{2}{|c|}{ Gilmore et al. (2004) } & \multicolumn{2}{|c|}{ Qc Qr Qi Qs Qg } & \multicolumn{2}{|l|}{2013} \\
\hline
\end{tabular}

Fig. 1 WRF modeling domains (black box) covers northwest and north India

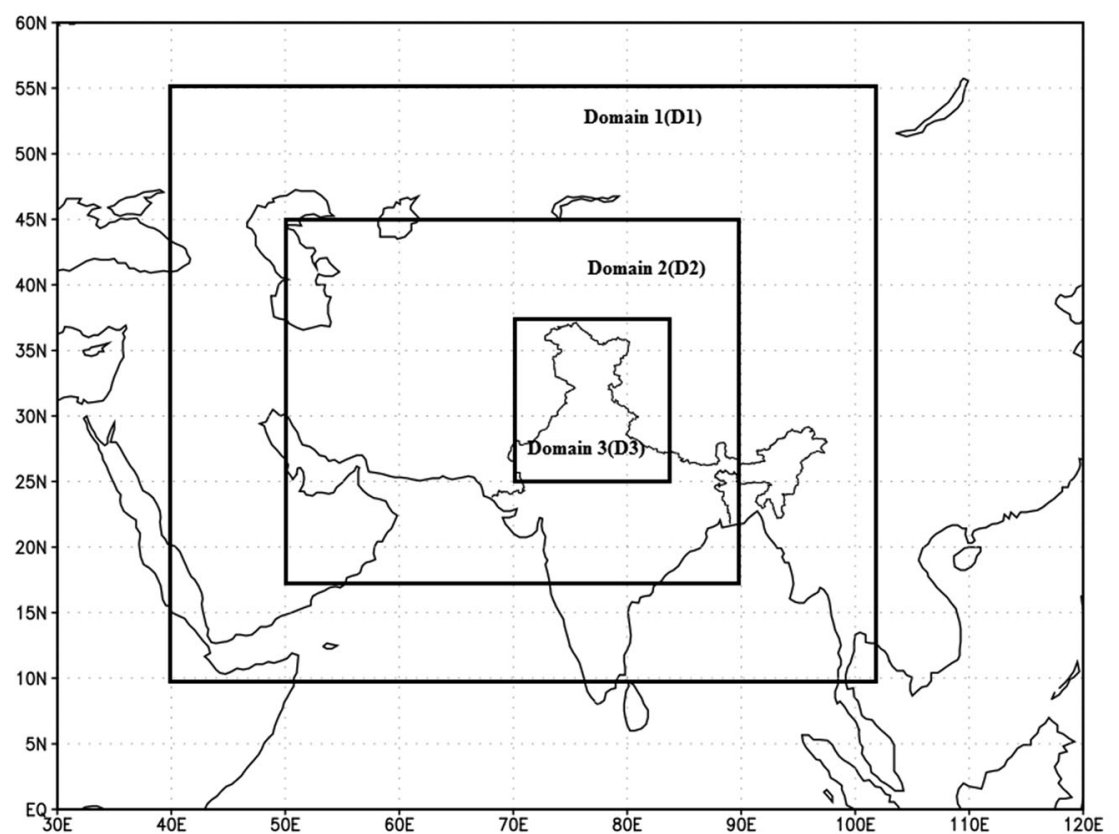

GRADS: COLA/IGES

$2015-04-07-12: 57$

\section{Model, data, experimental design and evaluation methodology}

\section{Model used}

The model used in this study is the Weather Research and Forecasting (WRF) model (Version v3.5.1) which is a widely used community mesoscale model. This version of the WRF model uses the Eulerian mass coordinate and is referred to as the Advanced Research WRF (ARW) developed by the National Center for Atmospheric Research (NCAR). It uses the fully compressible non-hydrostatic equations with hydrostatic option and mass-based terrain following coordinate. The horizontal grid is the Arakawa-C grid. The model can simulate both idealized and real-data cases with various lateral boundary condition options. The model supports one way, two-way, and moving nest options (Skamarock et al. 2008). A brief description of the model configuration and the different nested domains used in this study is given in Table 2 and Fig. 1 respectively. In the present study, three nested domains with resolutions of 81,27 and $9 \mathrm{~km}$ cover northwest and north India. Domain 1 is the mother domain and 
Table 4 RMSE and RSR in bracket based on the model forecasts of precipitation (mm/day) (PREC), 500 hpa geopotential height (m) (GPH) and $500 \mathrm{hPa}$ wind $(\mathrm{m} / \mathrm{s})(\mathrm{CIRC})$ from different experiments (physics configurations) for (a) WD case 1, 2 and (b) WD case 3, 4

\begin{tabular}{|c|c|c|c|c|c|c|}
\hline \multirow[t]{2}{*}{ (a) } & \multicolumn{3}{|l|}{ WD case 1} & \multicolumn{3}{|l|}{ WD case 2} \\
\hline & PREC & GOPT & CIRC & PREC & GOPT & CIRC \\
\hline STDEV $_{\mathrm{obs}}$ & 8.5551 & 67.2763 & 7.7728 & 6.6590 & 67.7515 & 6.2377 \\
\hline \multicolumn{7}{|l|}{ RMSE (RSR) } \\
\hline Experiment 1 & $4.2604(0.50)$ & $9.6234(0.14)$ & $5.2722(0.68)$ & $4.1482(0.62)$ & $10.0235(0.15)$ & $4.6897(0.75)$ \\
\hline Experiment 2 & $4.1607(0.49)$ & $9.7857(0.15)$ & $5.228(0.67)$ & $4.3367(0.65)$ & $10.0987(0.15)$ & $4.6235(0.74)$ \\
\hline Experiment 3 & $4.1865(0.49)$ & $9.5028(0.14)$ & $4.8513(0.62)$ & $4.044(0.61)$ & $10.1358(0.15)$ & $4.7253(0.76)$ \\
\hline Experiment 4 & $4.2618(0.49)$ & $9.5789(0.14)$ & $5.1467(0.66)$ & $4.7878(0.72)$ & $10.0235(0.15)$ & $4.6987(0.75)$ \\
\hline Experiment 5 & $\mathbf{3 . 5 9 5 8}(0.42)$ & $9.4893(0.14)$ & $4.9246(0.63)$ & $\mathbf{3 . 9 0 6 9}(0.59)$ & $9.9924(0.15)$ & $4.2056(0.67)$ \\
\hline \multirow[t]{2}{*}{ (b) } & \multicolumn{3}{|l|}{ WD case 3} & \multicolumn{3}{|l|}{ WD case 4} \\
\hline & PREC & GOPT & CIRC & PREC & GOPT & CIRC \\
\hline STDEV $_{\text {obs }}$ & 13.1256 & 67.9838 & 7.0578 & 12.7595 & 64.2063 & 7.6464 \\
\hline \multicolumn{7}{|l|}{ RMSE (RSR) } \\
\hline Experiment 1 & $5.1905(0.40)$ & $9.8794(0.15)$ & $4.7346(0.67)$ & $4.7413(0.37)$ & $9.9786(0.16)$ & $5.1338(0.67)$ \\
\hline Experiment 2 & $5.0835(0.39)$ & $9.7845(0.14)$ & $4.7248(0.67)$ & $4.8036(0.38)$ & $9.9873(0.16)$ & $5.1731(0.68)$ \\
\hline Experiment 3 & $4.2402(0.32)$ & $9.6879(0.14)$ & $4.605(0.65)$ & $4.2123(0.33)$ & $9.8567(0.15)$ & $4.9136(0.64)$ \\
\hline Experiment 4 & $4.7059(0.36)$ & $9.9873(0.15)$ & $4.8892(0.69)$ & $4.6756(0.37)$ & $9.876(0.15)$ & $5.2243(0.68)$ \\
\hline Experiment 5 & $\mathbf{4 . 1 9 1 4}(0.32)$ & $\mathbf{9 . 6 1 0 6}(0.14)$ & $\mathbf{4 . 4 7 8 3}(0.63)$ & $\mathbf{4 . 0 2 6 9}(0.32)$ & $9.932(0.15)$ & $4.7297(0.62)$ \\
\hline
\end{tabular}

Bold indicates the lowest root mean square error in the column

there are two inner domains within domain 1. All the domains are provided with feedback option.

\section{Data used}

Initial and boundary conditions for the model integration are taken from the NCEP High Resolution Global Forecast System (GFS) with $1^{\circ} \times 1^{\circ}$ spatial resolution and temporal resolution of $6 \mathrm{~h}$. For model validation different observational datasets have been used. For precipitation verification, a spatial resolution $0.25^{\circ} \times 0.25^{\circ}$ long period (1901-2013) daily gridded rainfall data over the Indian main land (Pai et al. 2014) by the India Meteorological Department (IMD) has been used.

Other parameters were validated with ERA-Interim of the European Centre for Medium-Range Weather Forecasts (ECMWF). This is a global atmospheric reanalysis data from 1979 to present. The spatial resolution of the data set is approximately $80 \mathrm{~km}$ (T255 spectral) on 60 vertical levels from the surface up to $0.1 \mathrm{hPa}$ (Dee et al. 2011).

\section{Experimental design}

The WRF physics options fall into several categories, each contains several choices. In the present study, Numerical experiments have been carried out by changing the Microphysics (MP) Category (shown in Tables 2, 3a) while keeping the other parameterization schemes fixed.
Microphysics schemes have commonly been referred to as grid-scale precipitation schemes. A full description (Mass variables, Number variables, various processes etc.) of Microphysics Category with each scheme is available in the model description document (Skamarock et al. 2008).

In addition to the microphysics schemes the role of various other parameterization schemes, which represents the processes at a subgrid scale is also very important.

Based on previous simulation studies by Azadi et al. (2001), Dimri and Chevuturi (2014) done for the WDs over the same region, the following parameterization schemes have been selected: Kain-Fritsch (KF) (Kain 2004) for cumulus; unified Noah land-surface model (Noah) (Chen and Dudhia 2001) for land surface; Yonsei University (YSU) (Hong and Lim 2006) for planetary boundary layer; MM5 (Monin-Obukhov) scheme (Paulson 1970) for surface layer; rapid radiative transfer model (RRTM) (Mlawer et al. 1997) for longwave radiation and Dudhia (1989) for shortwave radiation. Five experiments for producing 24-h forecasts have been carried out using the different Physics options as shown in Table 3a.

\section{Evaluation methodology}

Sensitivity and error statistics of precipitation (PREC; $\mathrm{mm} /$ day), wind (CIRC; $\mathrm{m} / \mathrm{s}$ ) and geopotential heights $(\mathrm{GPH} ; \mathrm{m})$ are analyzed to examine model sensitivity and identify best physics options suited for this region during the passage of the weather system. 

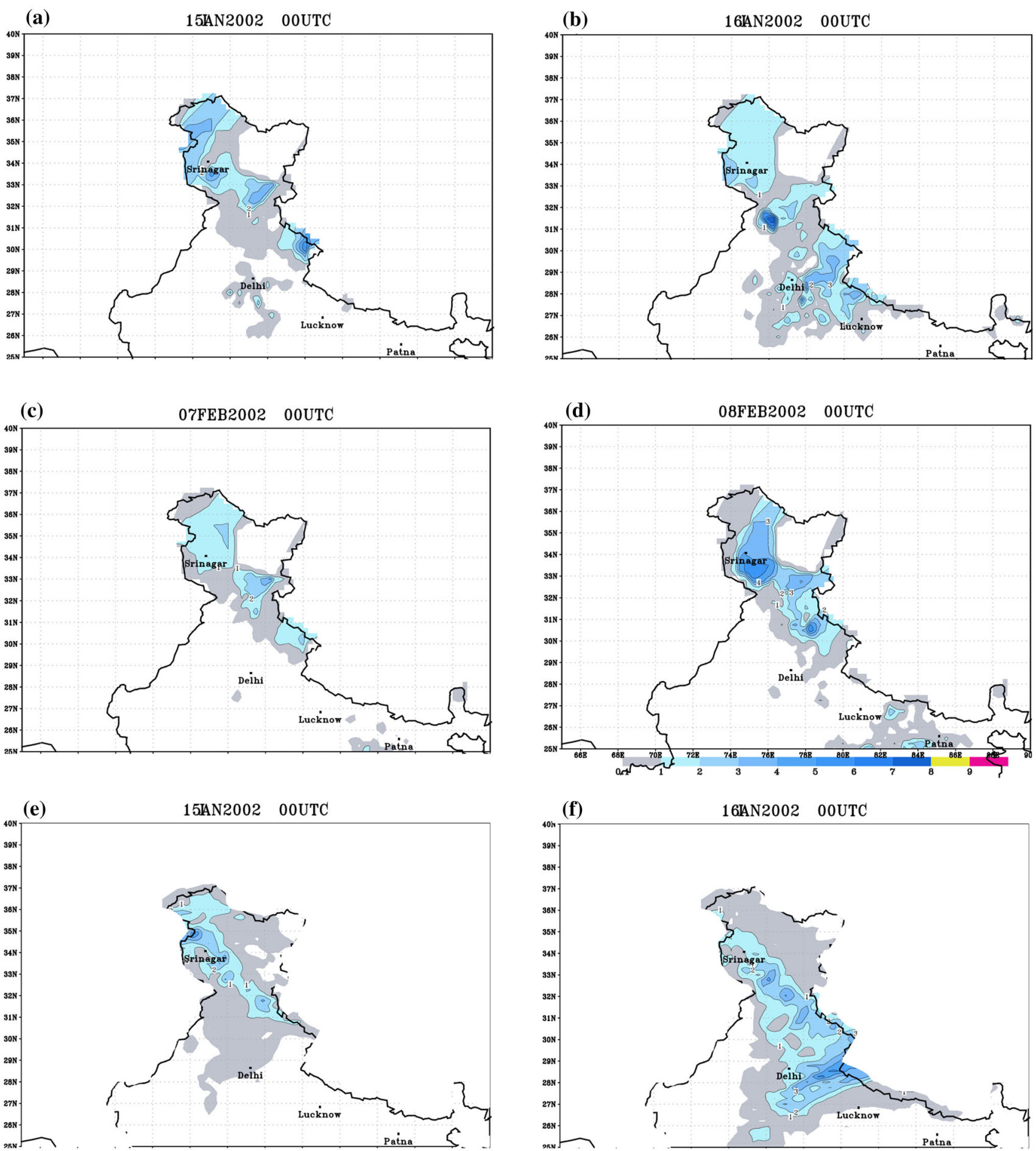

15AN2002 00UTC

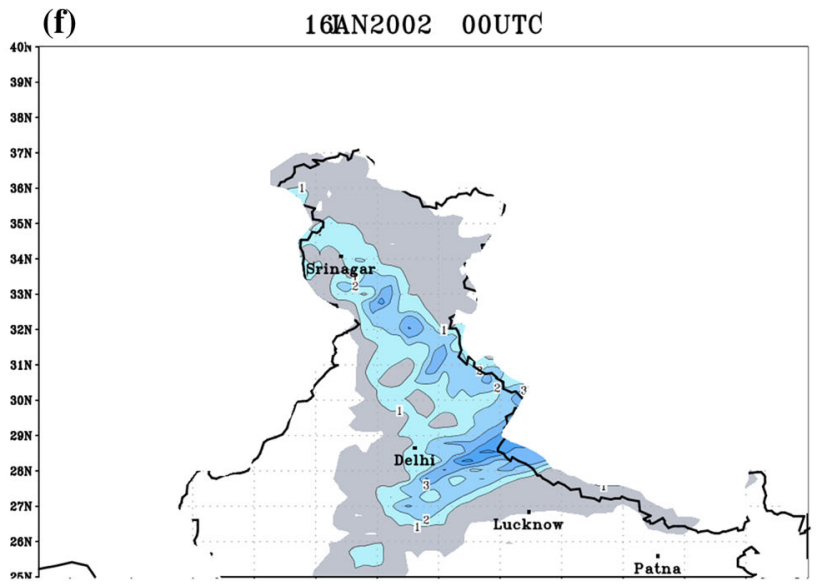

Fig. 2 Daily rainfalls (mm/day) based on a-d IMD's and e-h model simulated for 15th January 2002, 16th January 2002 of WD case 1 and 7th February 2002, 8th February 2002 of WD case 2 respectively

Root mean square error is used to examine model sensitivity. It is mathematically defined, (Singh et al. 2004; Wilks 2006) as

$R M S E=\sqrt{\frac{\sum_{i=1}^{n}\left(X_{i}-O_{i}\right)^{2}}{n}}$.
Standard deviation of observed data $\left(\mathrm{STDEV}_{\mathrm{obs}}\right)$ is mathematically defined,

$\operatorname{STDEV}_{\mathrm{obs}}=\sqrt{\frac{\sum_{i=1}^{n}\left(O_{i}-O_{\text {mean }}\right)^{2}}{n}}$ 

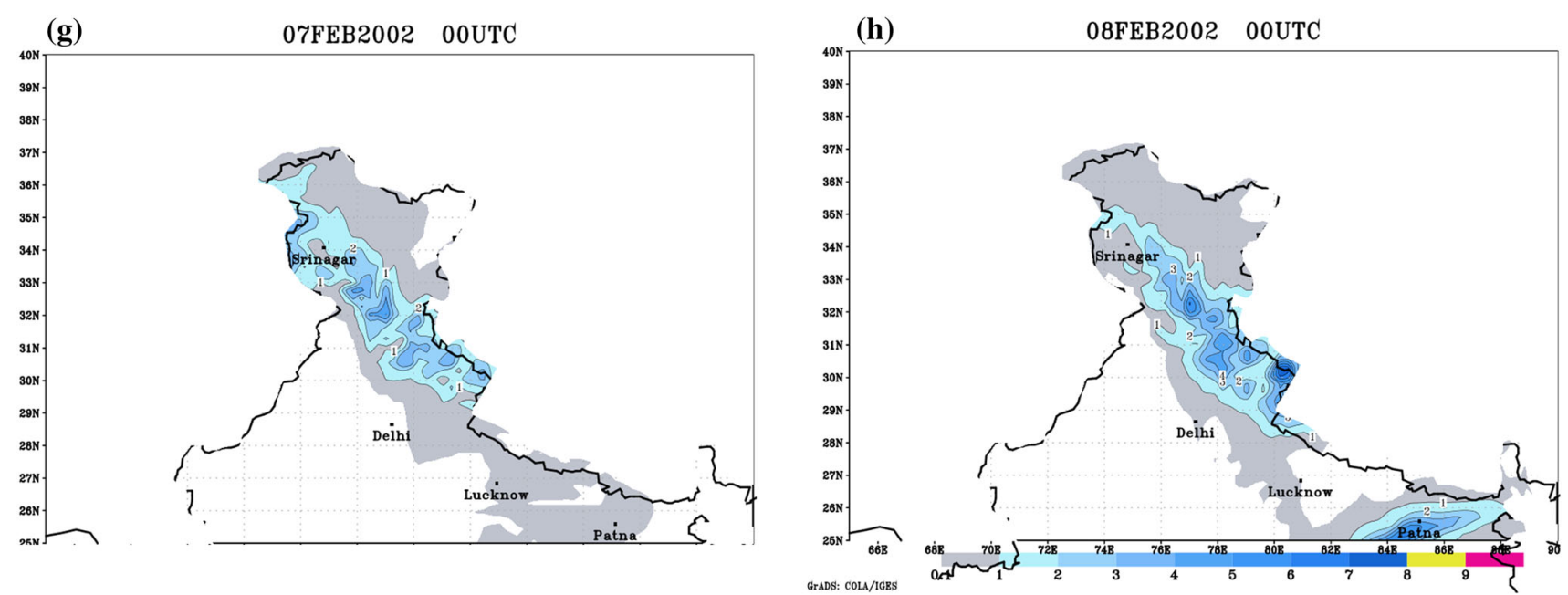

Fig. 2 continued

where $\mathrm{n}$ is the total number of evaluated grid points over space, $\mathrm{X}_{\mathrm{i}}$ and $\mathrm{O}_{\mathrm{i}}$ are the model and observed precipitation for ith point $O_{\text {mean }}$ is the value averaged over space for observed analysis.

RMSE is calculated over the domain area $26^{\circ} \mathrm{N}-40^{\circ} \mathrm{N}$ and $70^{\circ} \mathrm{E}-85^{\circ} \mathrm{E}$ which covers the north west and north India. In each grid or grid point model output is compared with the observation in order to calculate RMSE. The Model accumulated rainfall was compared with IMD observational dataset. For geopotential height and winds, ERA interim observational dataset is used. In addition to these statistics RMSE-observations standard deviation ratio (RSR) is also evaluated.

$R S R=\frac{R M S E}{\mathrm{STDEV}_{\mathrm{obs}}}$

RSR standardizes RMSE using the observations standard deviation. RSR varies from the optimal value of 0 , which indicates zero RMSE or residual variation and therefore perfect model simulation, to a large positive value. Lower RSR and lower RMSE indicate better model simulation. If RSR greater than or equal to 1 (high) then Skill of the model is poor so it does not make any sense to evaluate the best physics options suited for this region during the weather system (Morias et al. 2007). An experiment that gives the Lowest RMSE (RSR) will be determined from the five simulations. The configuration of this experiment may be the best combination of physics options suited for the region to capture the main characteristics of the various parameters associated with the WDs.

\section{Results and discussion}

\section{Sensitivity of the model forecast and to identify best physics options}

The model forecasts of precipitation (PREC; $\mathrm{mm} /$ day), wind $(\mathrm{CIRC} ; \mathrm{m} / \mathrm{s})$ and geopotential heights $(\mathrm{GPH} ; \mathrm{m})$ from five physics configurations have been assessed with respective observational datasets for the four cases of WDs that affected the northwest India. Table $4 \mathrm{a}, \mathrm{b}$ show RMSE and RSR in bracket based on the Model forecasts of precipitation (mm/day) (PREC), $500 \mathrm{hpa}$ geopotential height (m) $(\mathrm{GPH})$ and $500 \mathrm{hPa}$ wind $(\mathrm{m} / \mathrm{s})$ (CIRC) from different experiments (physics configurations) for WD case 1,2 and WD case 3, 4 respectively.

RMSE and RSR are evaluated for all the model domains, but for the sake of brevity the Table 4 illustrates the values of the first model domain $(81 \mathrm{~km})$ only. It is seen that RSR is always less than one which shows that the means skill (performance) of the model is good for forecasting these cases of WDs. It is observed that, most of the time RMSE and RSR has been the lowest for Experiment 5 .

In the Experiment 5, National Severe Storms Laboratory (NSSL) 1-moment (Gilmore et al. 2004) scheme used as a microphysics parameterization scheme. It is developed at the National Severe Storms Laboratory. A single-moment bulk microphysics scheme with multiple ice precipitation categories is described. It has in addition two liquid hydrometers, snow (ice crystal aggregates), and various categories of graupel with different densities and intercepts. It also has predictive equations for the specific 

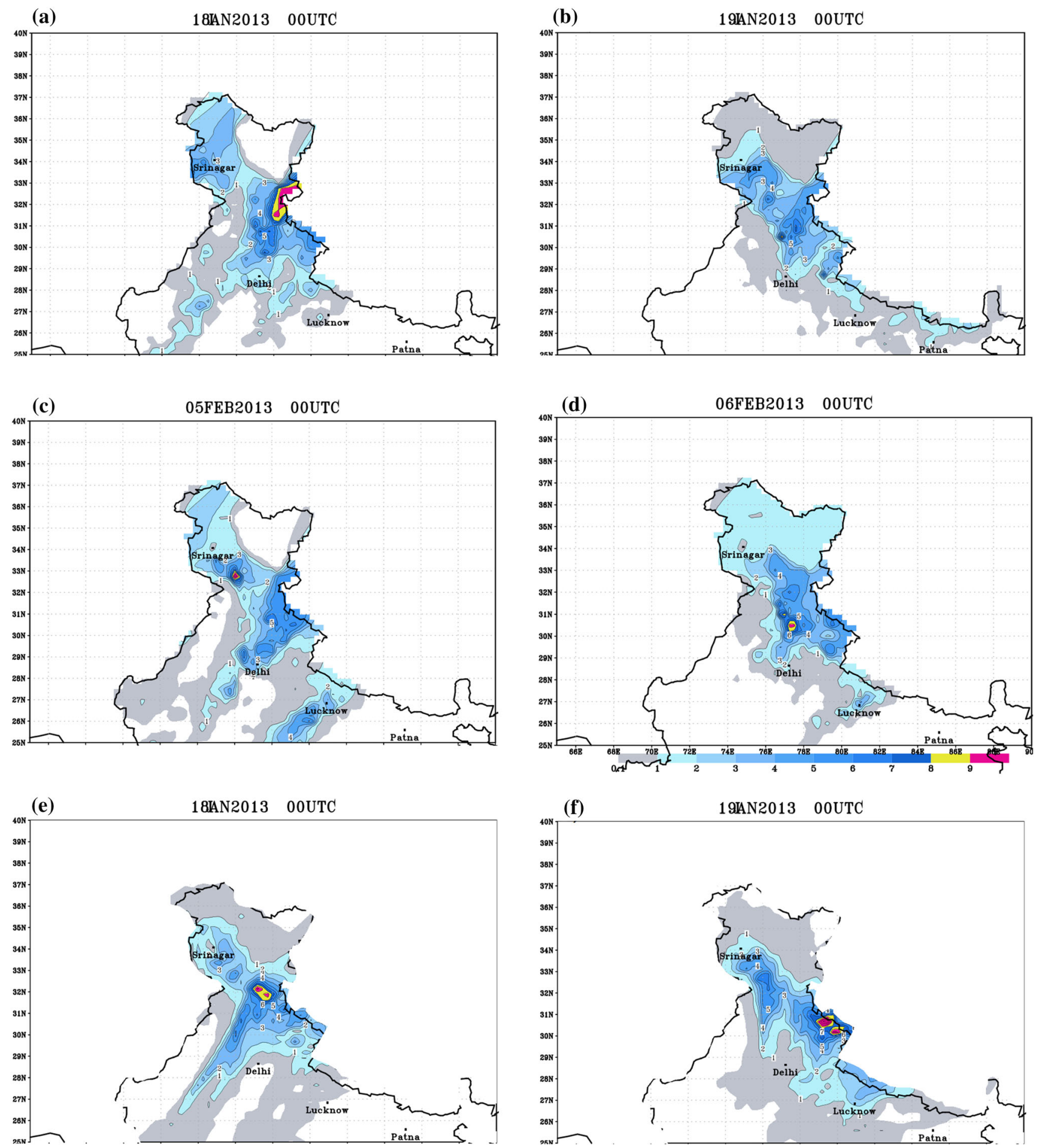

18 AN2013 00UTC

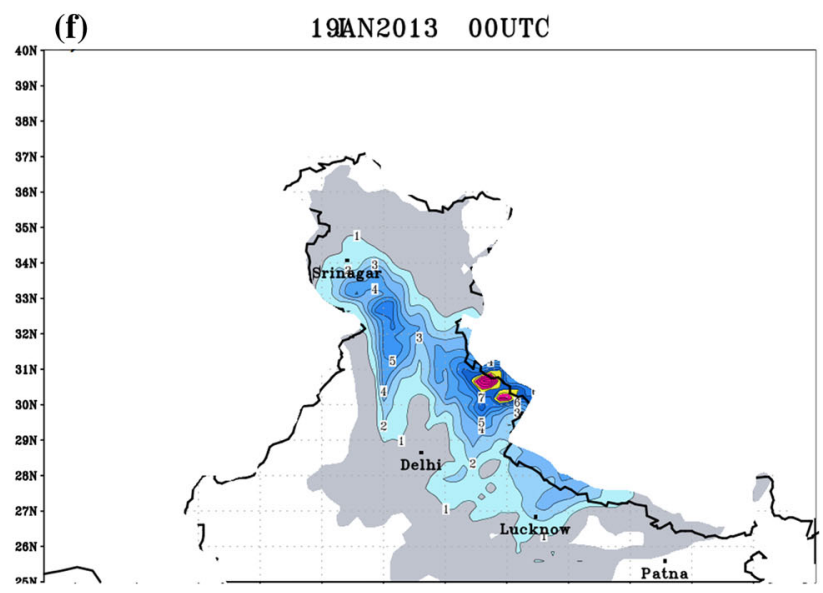

Fig. 3 Daily rainfalls (mm/day) based on a-d IMD's and e-h model simulated for 18th January 2013, 19th January 2013 of WD case 3 and 5th February 2013, 6th February 2013 of WD case 4 respectively

humidity of forms of particle like cloud water $\left(q_{c}\right)$, cloud ice $\left(q_{i}\right)$,snow $\left(q_{s}\right)$, rain $\left(q_{r}\right)$ and graupel $\left(\mathrm{q}_{\mathrm{g}}\right)$ (see Table $3 \mathrm{~b}$ ). The specific humidity for the larger precipitation categories (graupel, hail, and rain) are defined by Marshall-Palmer exponential size distributions (Marshall and Palmer 1948). These features may be responsible for proper depiction of 
sub grid level phenomenon over the region and hence lower the errors.

The performance of the combination of NSSL one moment, KF, Noah, YSU, MM5 schemes as microphysics, cumulus parameterization, Land surface, Planetary Boundary layer and Surface layer respectively are best compared to the other schemes used in this study. Thus discussions on dynamical structure of WDs are based on these combinations of the model physics.

\section{To study dynamical structure of WDs}

Dynamical structure of the WDs simulated by the model with the Physics configuration of experiment 5 is discussed here. Figure $2 \mathrm{a}-\mathrm{d}$ shows daily rainfalls $(\mathrm{mm} / \mathrm{day})$ for 15 th and 16th January 2002, of WD case 1 and 7th and 8th February 2002, of WD case 2 respectively based on IMD's gridded rainfall data and Fig. 2e-f shows for model simulated rainfall.

On 15th January 2002, the observed rainfall distribution (see Fig. 2a) shows widespread rainfall over many places over NW India and the model simulation also shows almost the same pattern which can be seen in the observed rainfall (see Fig. 2a, e). On 16th January 2002, the observed rainfall distribution shows, the maxima of precipitation has shifted towards South-East direction (see Fig. 2b). The model could produce the maxima of precipitation which can be seen in the observed rainfall (see Fig. 2b, f). On 7th February 2002, moderate rainfall in the range 1-2 cm over some parts of Western Himalayan region were observed (see Fig. 2c). Model could produce rainfall of the same range over the same region as seen in
Fig. $4500 \mathrm{hPa}$ geopotential (m, contour), wind (m/s, arrow) and region with wind speed more than $25 \mathrm{~m} / \mathrm{s}$ depicted in grey shade $\mathbf{a}-$ $\mathbf{d}$ with Era-interim data and $\mathbf{e}-\mathbf{h}$ model simulation valid for 00UTC for 15th January 2002, 16th January 2002 of WD case 1 and 7th February 2002, 8th February 2002 of WD case 2 respectively

observed spatial distribution pattern (see Fig. 2c, g). On 8th February 2002, rather heavy rainfall is seen over many places of East India (see Fig. 2d). The Model could produce rainfall over the region but over-predicted the rainfall (see Fig. 2d, h).

Figure $3 \mathrm{a}-\mathrm{d}$ shows daily rainfalls (mm/day) for 18 th and 19th January 2013, of WD case 3 and 5th and 6th February 2013 of WD case 4 respectively based on IMD's gridded rainfall data and Fig. 3(e-f) shows the model simulated rainfall. On 18th January 2013, the observed rainfall distribution (Fig. 3a) shows a belt of moderate to heavy rainfall over the Western Himalayan region with peak centered near lat $32^{\circ} \mathrm{N}$ and $79^{\circ} \mathrm{E}$ (Approximately $10 \mathrm{~cm}$ ) was observed. Figure $3 \mathrm{e}$ presents the model forecast for same period. The model could produce moderate to heavy rainfall over Western Himalayan region with peak centered near lat $32^{\circ} \mathrm{N}$ and $77^{\circ} \mathrm{E}$ (Approximately $10 \mathrm{~cm}$ ). The model simulated spatial distribution pattern shows widespread light to moderate rain over parts of North West India, which can be clearly discernible in the observed rainfall (see Fig. 3a, e). On 19th January 2013, again Precipitation belt $(1-6 \mathrm{~cm})$ was confined mainly over the Western Himalayan region. Also light to moderate rain was observed over parts of eastern India (see Fig. 3b). From Fig. 3f, it is seen that, the model could produce the precipitation belt over the Western Himalayan region, light to moderate rain is seen over
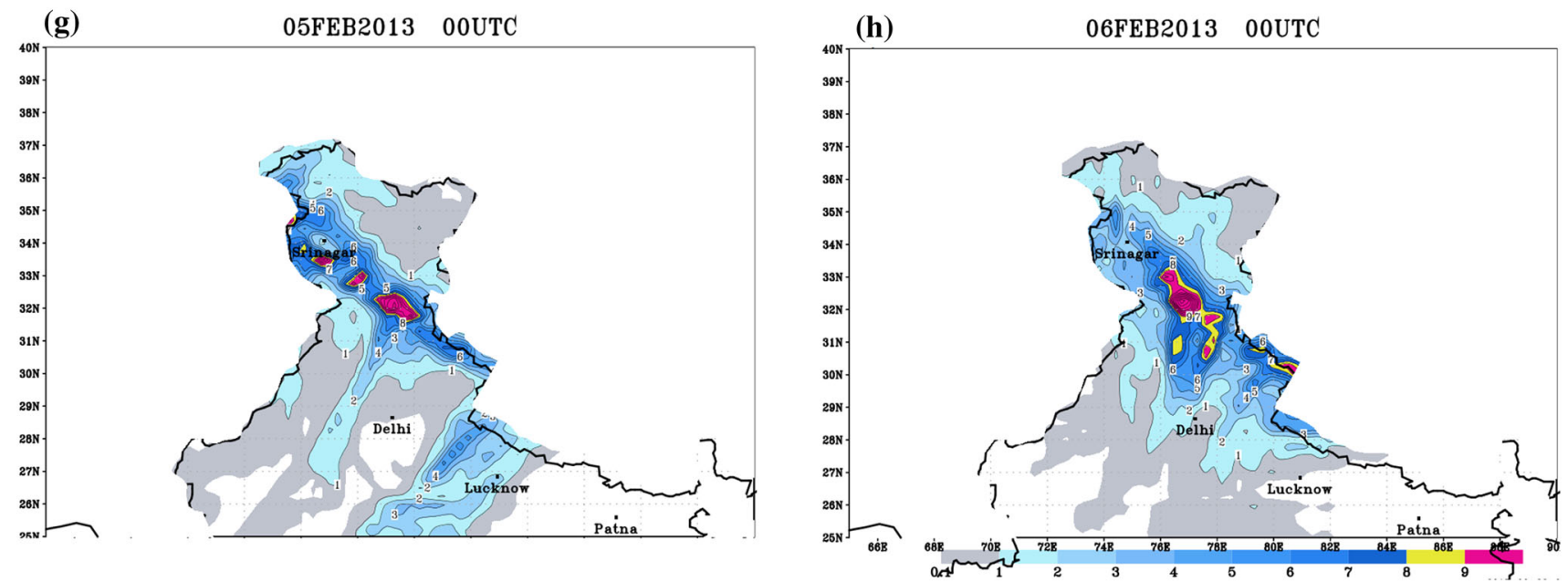

Fig. 3 continued 
(a)

15AN2002 00UTC

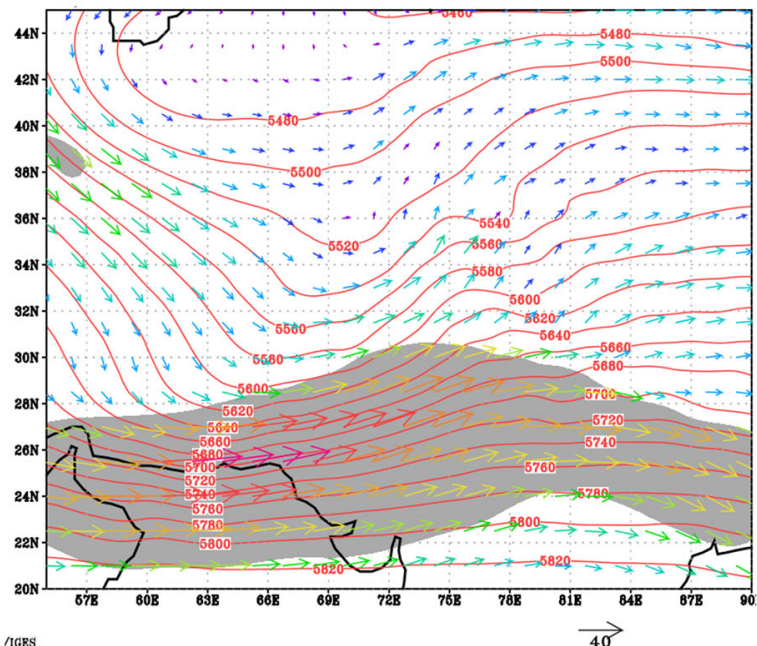

(c)

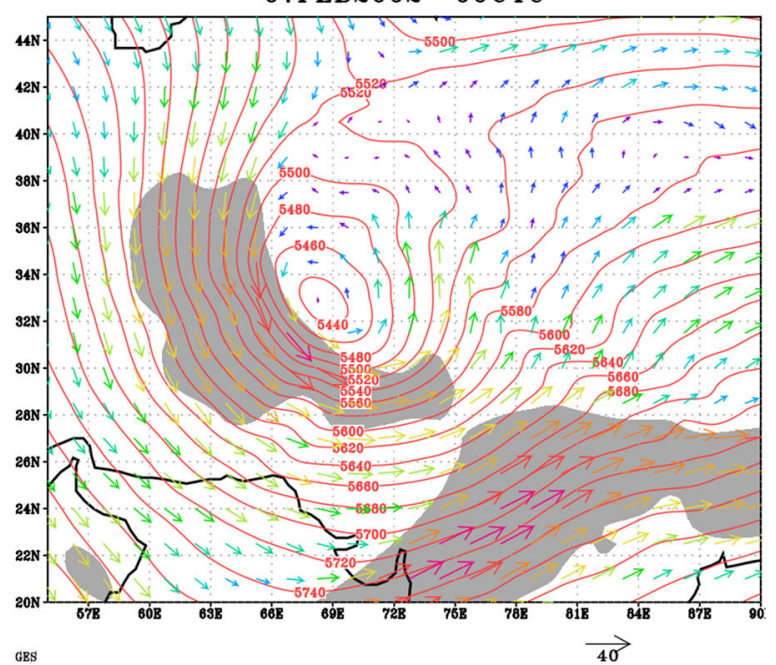

(e)

15AN2002 00UTC

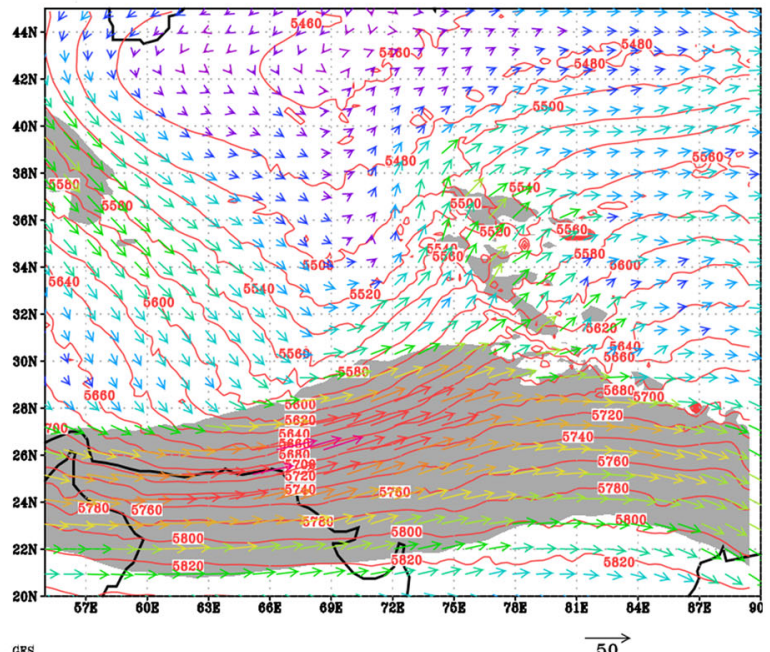

(b)

16AN2002 00UTC

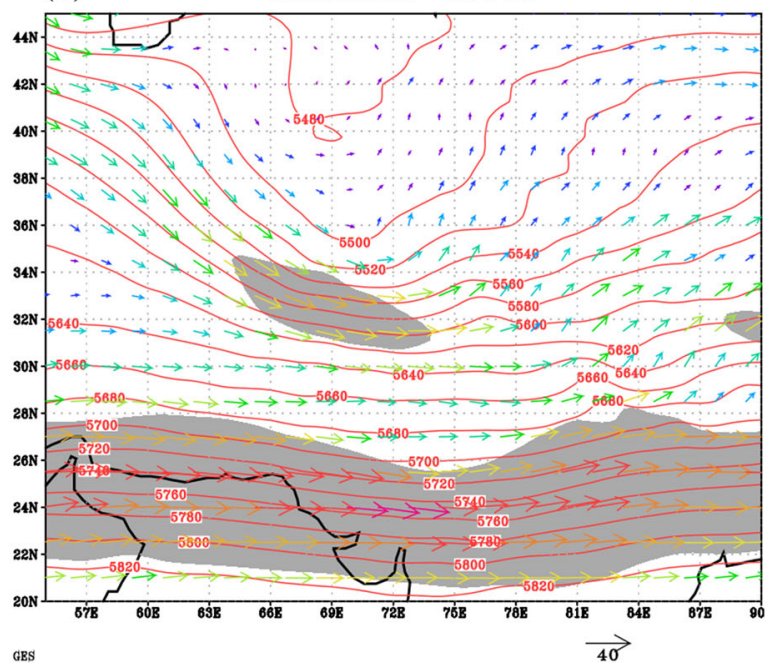

(d)

08FEB2002 00UTC

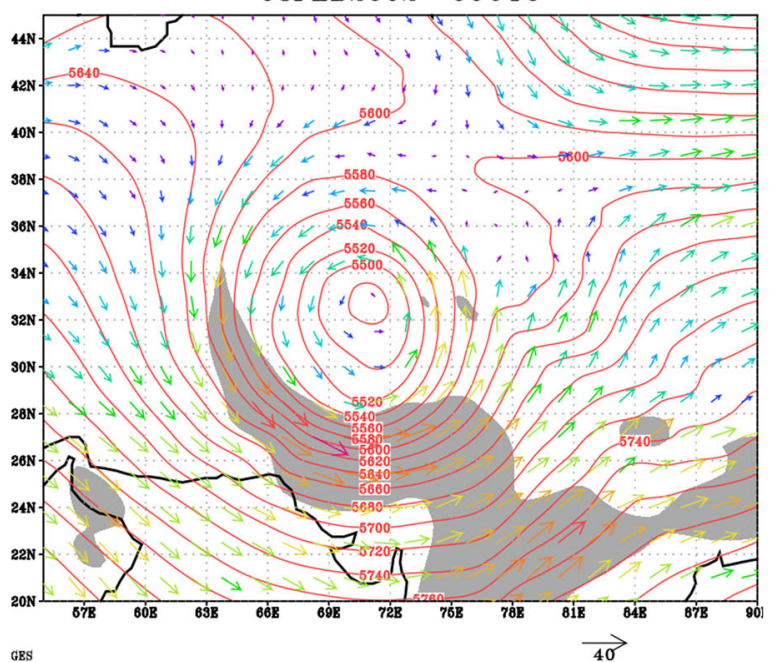

(f) 16AN2002 00UTC

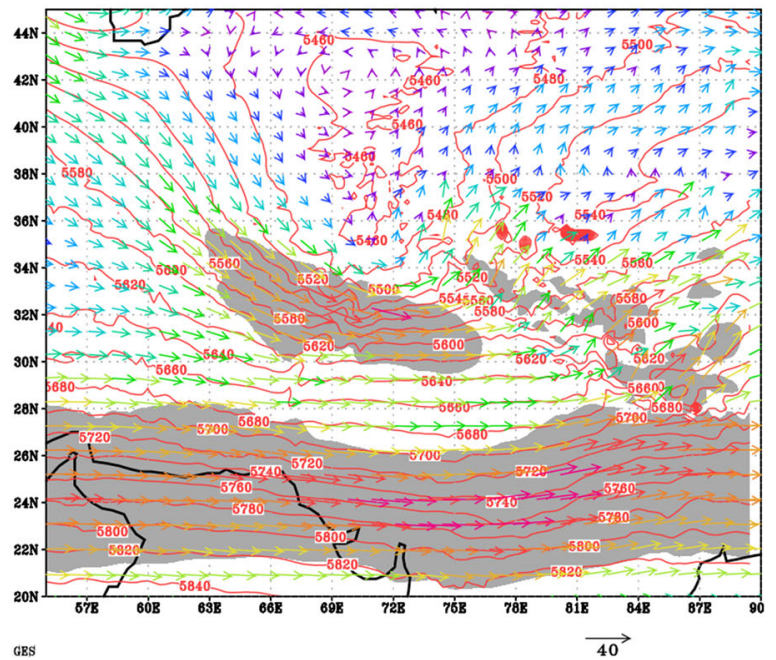


parts of eastern India. On 5th February 2013, Precipitation belt $(2-9 \mathrm{~cm})$ was confined mainly over the Western Himalayan region with peak centered near lat $33^{\circ} \mathrm{N}$ and $75^{\circ} \mathrm{E}(>9 \mathrm{~cm})$ light to rather heavy rain over parts of North West India can also be seen (see Fig. 3c). The model simulation could also produce the Precipitation belt over the same region, but over predicted the rainfall over some parts of the Western Himalayan region (see Fig. 3c, g). On 6th February 2013, heavy rainfall persisted over the Western Himalayan region (see Fig. 3d). From Fig. $3 \mathrm{~h}$, it is seen that the model could produce the Precipitation belt over same region. Figure $4 \mathrm{a}-\mathrm{d}$ presents $500 \mathrm{hPa}$ geopotential height (m, contour) and wind $(\mathrm{m} / \mathrm{s}$, arrow) based on Era-interim data and region with wind speed more than $25 \mathrm{~m} / \mathrm{s}$ is depicted in grey shade. Figure $4 \mathrm{e}-\mathrm{h}$ shows the model simulated values for 15 th and 16th January 2002 of WD case 1 and 7th and 8th February 2002, of WD case 2 respectively. Geopotential height approximates the actual height of a pressure surface above mean sea-level. Since cold air is denser than warm air, it causes pressure surfaces to be lower in colder air masses, while less dense, warmer air allows the pressure surfaces to be higher (Stull 2012). Thus, heights are lower in cold air masses, and higher in warm air masses. A line drawn in the presented figures connecting points of equal height (in meters) is called a height contour. That means, at every point along a given
Fig. $5500 \mathrm{hPa}$ geopotential (m, contour), wind (m/s, arrow) and region with wind speed more than $25 \mathrm{~m} / \mathrm{s}$ depicted in grey shade $\mathbf{a}-$ d with Era-interim data and $\mathbf{e}-\mathbf{h}$ model simulation valid for 00UTC for 18th January 2013, 19th January 2013 of WD case 3 and 5th February 2013, 6th February 2013 of WD case 4 respectively

contour, the values of geopotential height are same. Geopotential height is valuable for locating troughs and ridges which are the upper level counterparts of surface cyclones and anticyclones (Daniel et al 1997). From Fig. 4 a, it is seen that on 15 th January 2002 , a trough lay along longitude about $66^{\circ} \mathrm{E}$. Model simulation could produce the trough along longitude about $68^{\circ} \mathrm{E}$ (see Fig. 4e). Figure $4 \mathrm{~b}$ shows the trough has deepened and moved rapidly eastwards on 16th January 2002 and lay along longitude about $72^{\circ} \mathrm{E}$. Model simulation could produce the trough at the same position (see Fig. 4f). From Fig. 4c, it is seen that on 7th February 2002, the associated cyclonic circulation is over $30^{\circ} \mathrm{N}$ to $34^{\circ} \mathrm{N}$ and $68^{\circ} \mathrm{E}$ to $72^{\circ} \mathrm{E}$ region. The Model could capture the cyclonic circulation over the same region (see Fig. $4 \mathrm{~g}$ ). The model simulation shows that on 8th February 2002, the cyclonic circulation moved eastward (see Fig. 4h) which can also be seen in observed analysis (see Fig. 4d).

Figure $5 \mathrm{a}-\mathrm{d}$ presents $500 \mathrm{hPa}$ geopotential height $(\mathrm{m}$, contour) and wind ( $\mathrm{m} / \mathrm{s}$, arrow) based on Era-interim data and region with wind speed more than $25 \mathrm{~m} / \mathrm{s}$ is depicted in
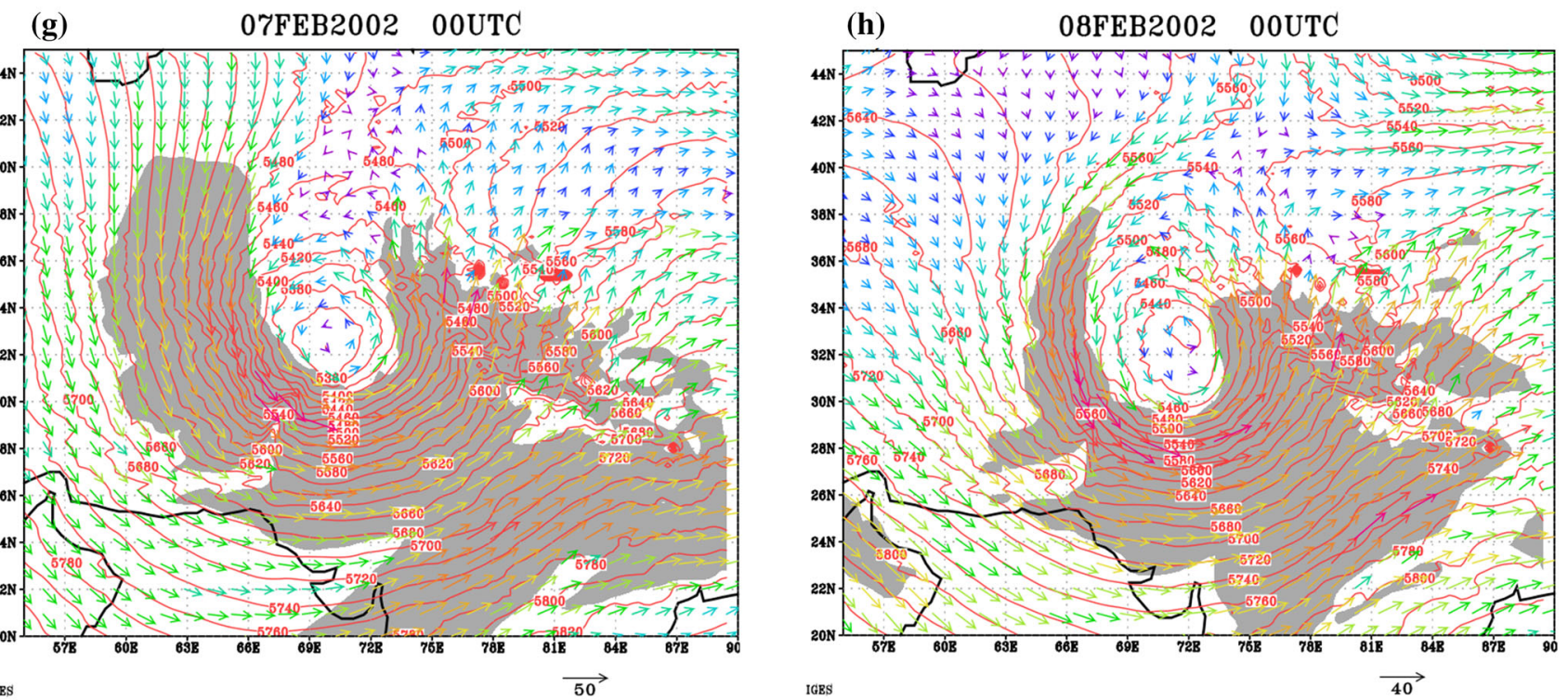

Fig. 4 continued 
(a)

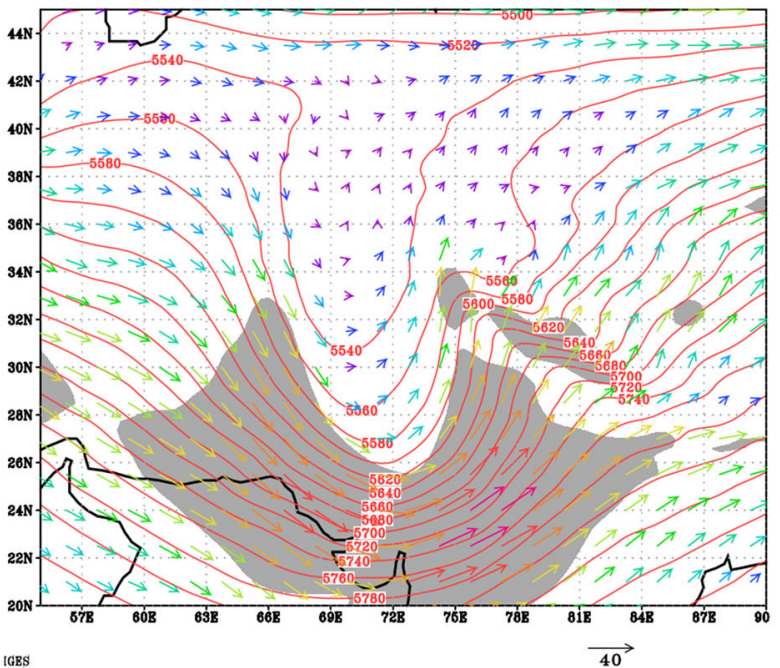

(c)

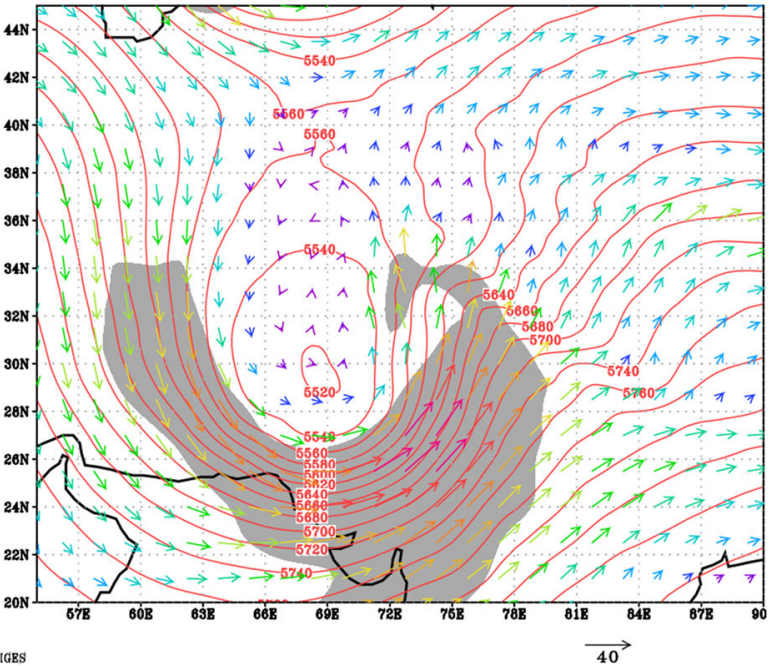

(e)

1 BAN2013 00UTC

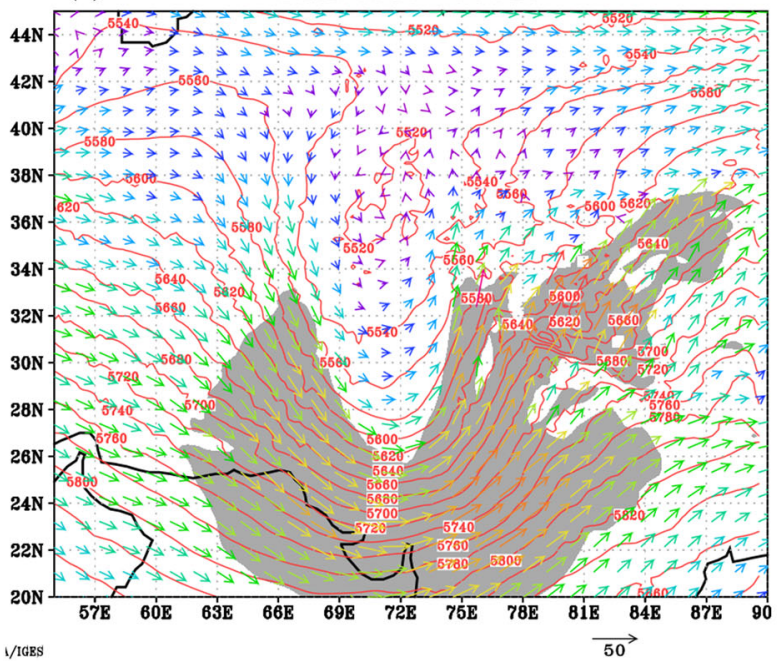

(b)

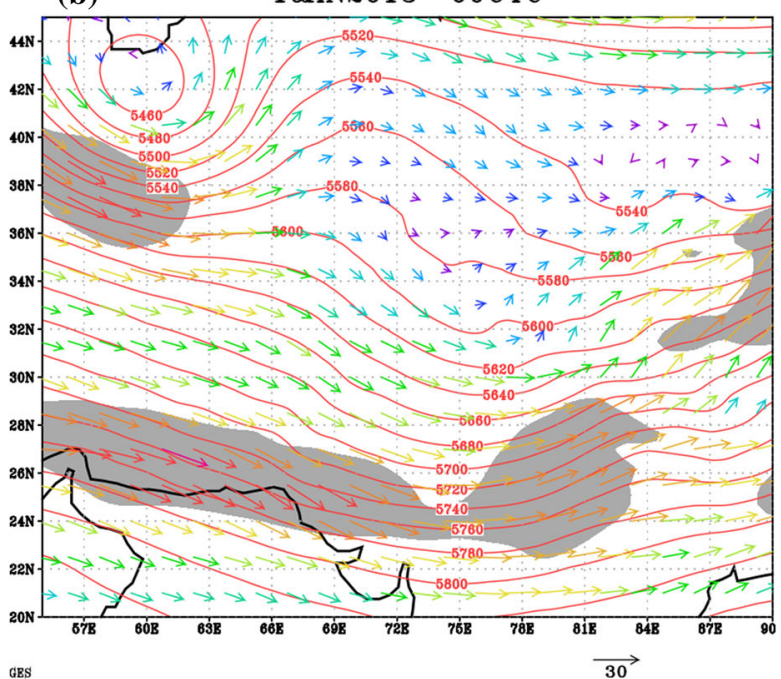

(d)

06FEB2013 00UTC

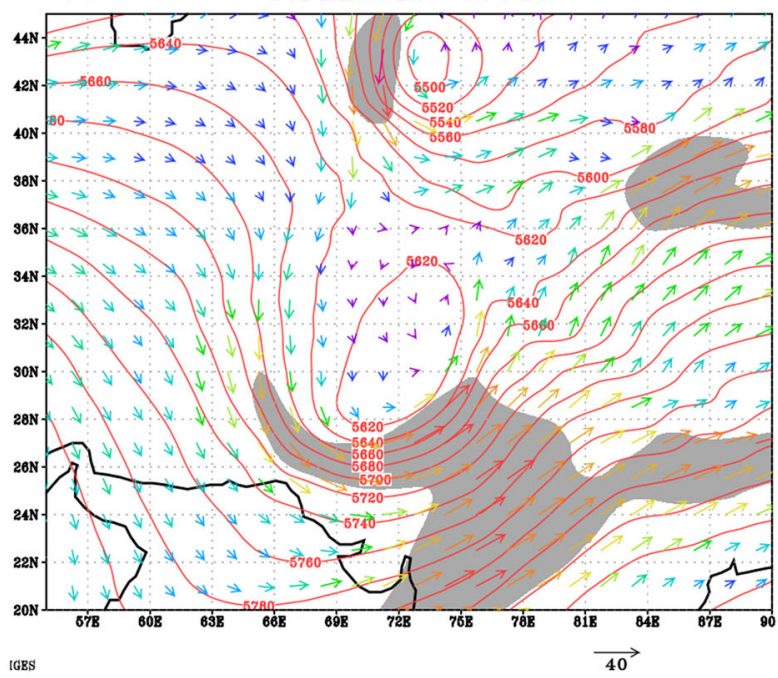

(f)

19AN2013 00UTC

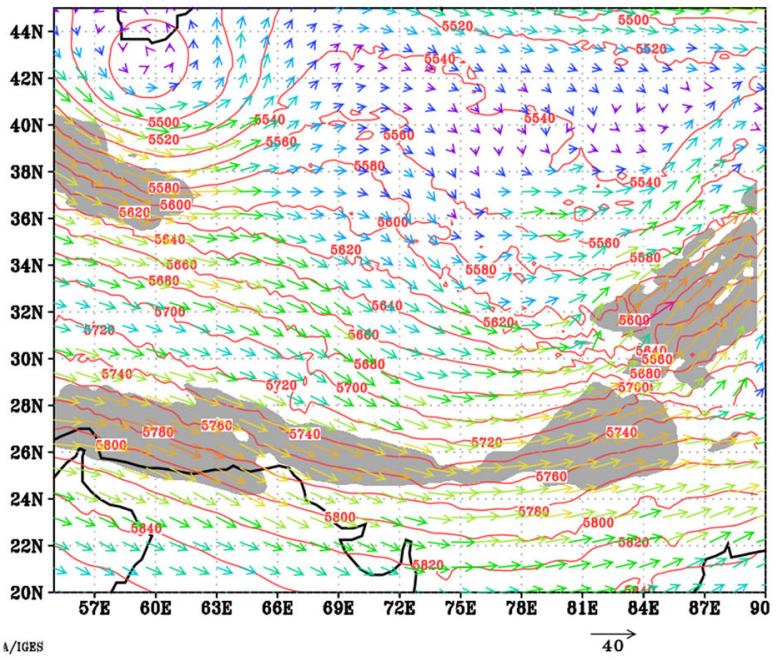


grey shade. Figure $5 \mathrm{e}-\mathrm{h}$ shows the model simulated values for 18th and 19th January 2013 of WD case 3 and 5th and 6th February 2013 of WD case 4 respectively. On 18th January 2013, well intensified trough lay along longitude about $70^{\circ} \mathrm{E}$ (see Fig. 5a). Model simulation could produce the trough at the same position (see Fig. 5e). The system became less marked on 19th January 2013 (see Fig. 5b) and model simulation could produce the same synoptic conditions (see Fig. 5f). From Fig. 5c, it is seen that the cyclonic circulation is over $30^{\circ} \mathrm{N}$ to $34^{\circ} \mathrm{N}$ and $68^{\circ} \mathrm{E}$ to $72^{\circ} \mathrm{E}$ region on 6th February 2013. The cyclonic circulation moved eastward and it became less marked on 7th February 2013 (Fig. 5d). The Model could produce the same synoptic conditions associated with the system (see Fig. 5c-f). During all the WDs, the model simulated geopotential height shows good accuracy in predicting low pressure area over the region. Figure $6 \mathrm{a}-\mathrm{h}$ presents the forecast error (model-observation) in $500 \mathrm{hpa}$ wind $(\mathrm{m} / \mathrm{s}$, arrow) and the region with bias (forecast error) more than $5 \mathrm{~m} / \mathrm{s}$ depicted in grey shade for 15th and 16th January 2002 (of WD case 1), 7th and 8th February 2002 (of WD case 2), 18th and 19th January 2013 (of WD case 3) and 5th and 6th February 2013 (of WD case 4) respectively. From Fig. 6a-h it is observed that, the model simulated wind pattern agrees very closely with the observation analysis. However, over western Himalayan region it shows a south westerly bias.

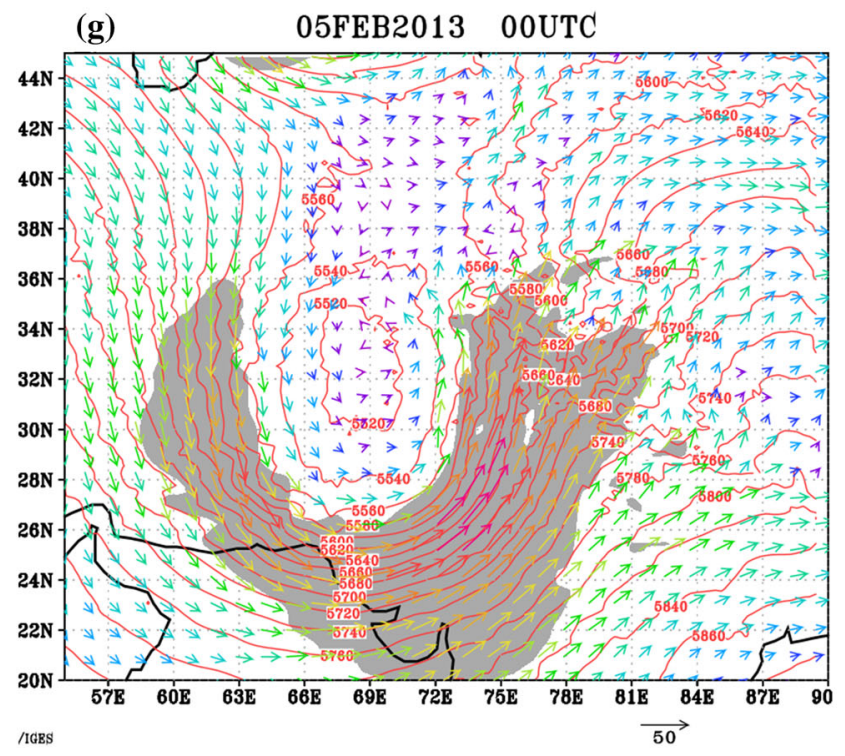

Fig. 6 Forecast error (model-observation) for $500 \mathrm{hPa}$ wind $(\mathrm{m} / \mathrm{s}$, arrow) and region with wind speed error more than $5 \mathrm{~m} / \mathrm{s}$ depicted in grey shade for $\mathbf{a}-\mathbf{h}$ for 15th January 2002, 16th January 2002 of WD case 1, 7th February 2002, 8th February 2002 of WD case 2, 18th January 2013, 19th January 2013 of WD case 3 and 5th February 2013, 6th February 2013 of WD case 4 respectively

\section{Conclusions}

The present study shows that performance of the combination of NSSL one moment, KF, YSU, RRTM and Dudhia schemes as a microphysics, cumulus, planetary boundary layer, longwave radiation and shortwave radiation parameterization schemes respectively gives a better simulation of the weather during WD's over North West India.

The characteristics of the various parameters associated with the WDs have been thoroughly studied. It is found that the intensity and movement of the precipitation distribution and circulation over the region is well predicted by the model. However, it shows a bias over the Himalayan region. During all the WDs, the model simulated geopotential height shows good accuracy in predicting low pressure areas over the region. The model simulated wind pattern agrees very closely with the observation analysis. However, over western Himalayan region it shows a south

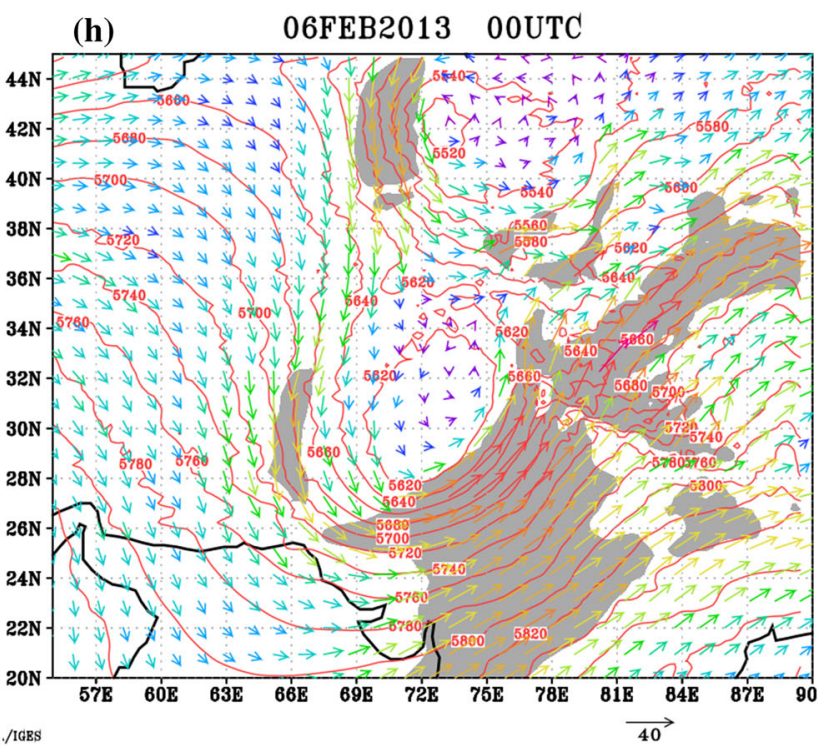

Fig. 5 continued 
(a)

15AN2002 00UTC

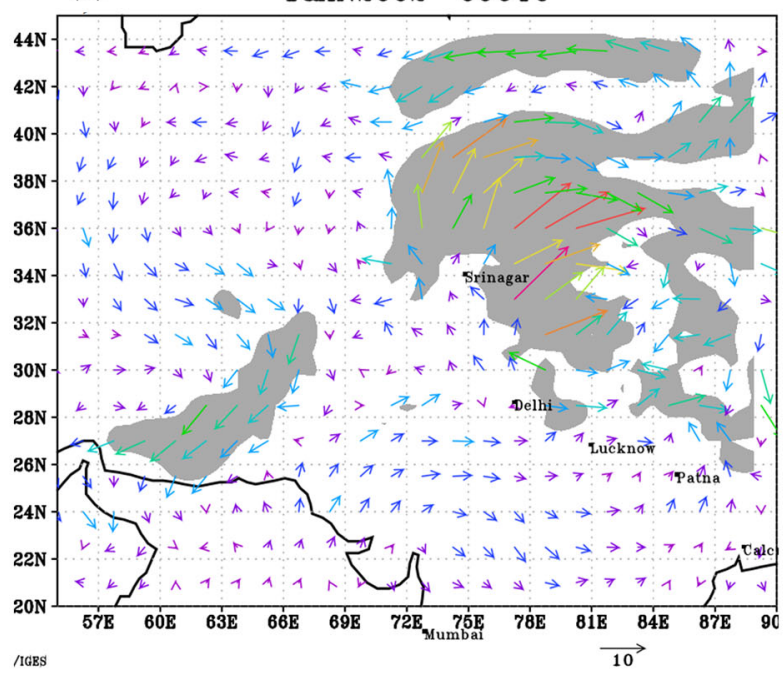

(c)

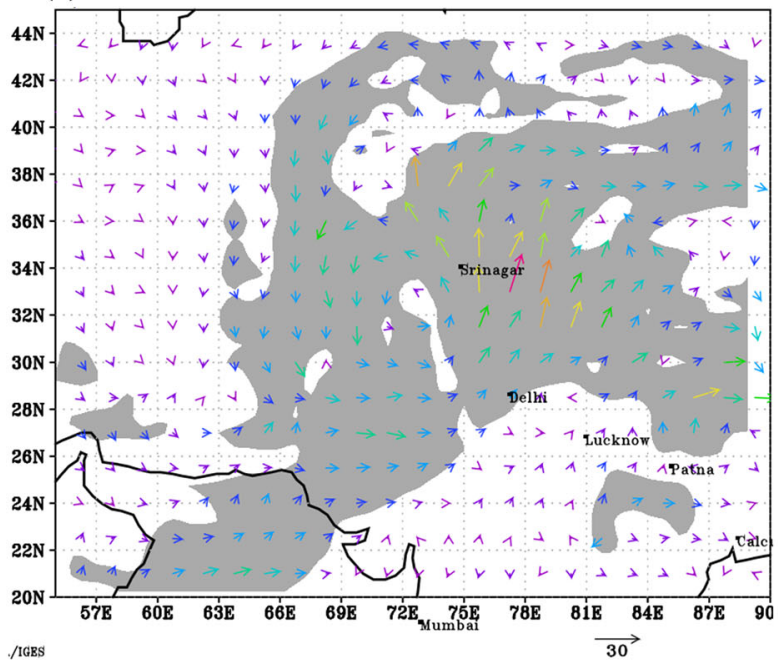

(e)

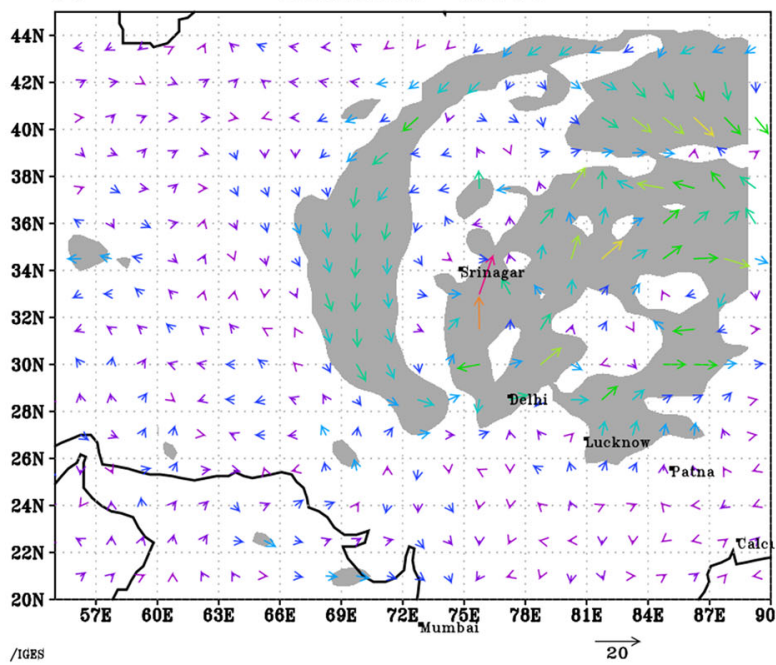

(b) 16AN2002 00UTC

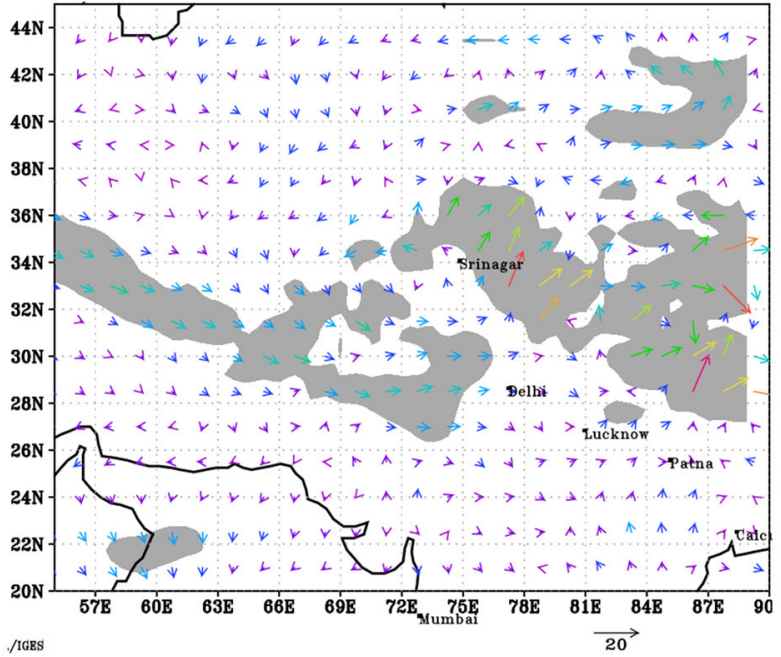

(d)

08FEB2002 00UTC

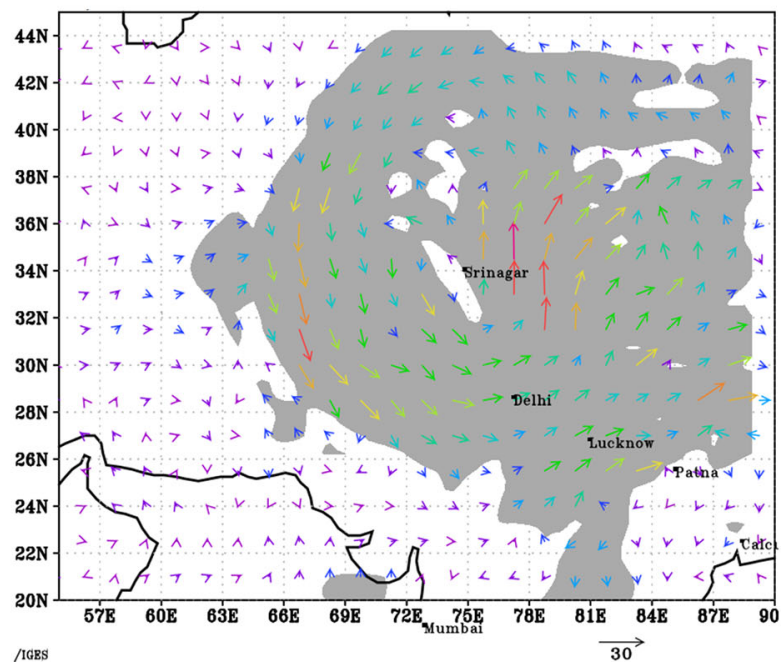

(f)

19AN2013 00UTC

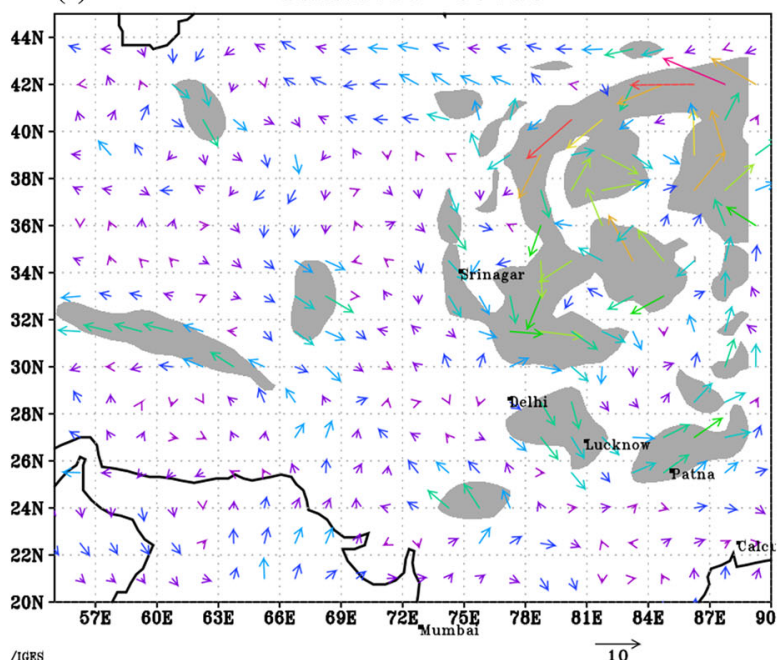

IIGBS 
(g)

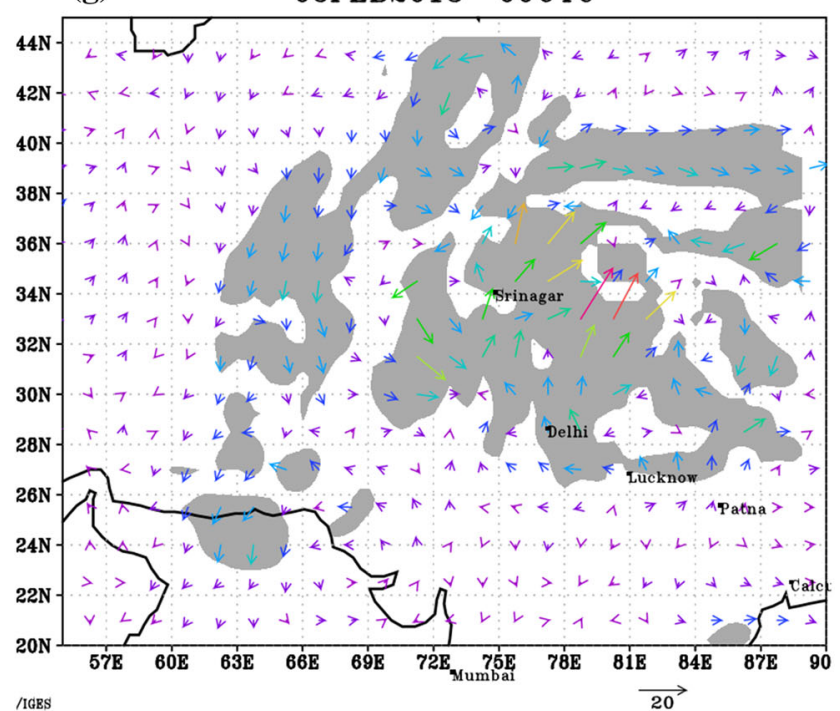

Fig. 6 continued

westerly bias. Further improvement in the model resolution (less than $1 \mathrm{~km}$ ), high resolution mountainous region and assimilation of satellite data in the analysis system are expected to improve the forecast accuracy further.

Acknowledgments We acknowledge NCEP/NCAR for the use of their GFS datasets and ECMWF for ERA-Interim datasets. We also acknowledge IMD for providing rainfall data for this study and Savitribai Phule Pune University (SPPU) for computing support.

\section{References}

Azadi M, Mohanty UC, Madan OP, Padmanabhamurty B (2001) Prediction of precipitation associated with western disturbances using a high-resolution regional model: role of parameterization of physical processes. Meteorol Appl 7:317-326

Borge R, Alexandrov V, José del Vas J, Lumbreras J, Rodríguez E (2008) A comprehensive sensitivity analysis of the WRF model for air quality applications over the Iberian Peninsula. Atmos Environ 42:8560-8574

Chen F, Dudhia J (2001) Coupling an advanced land-surface/ hydrology model with the Penn State/NCAR MM5 modeling system, part I: model description and implementation. Mon Weather Rev 129:569-585

Crétat J, Pohl B, Richard Y, Drobinski P (2012) Uncertainties in simulating regional climate of Southern Africa: sensitivity to physical parameterizations using WRF. Clim Dyn 38:613-634

Daniel B, David W et al (1997) Geopotential height. The University of Illinois Board of Trustees. http://ww2010.atmos.uiuc.edu/\% 28G1\%29/guides/mtr/cyc/upa/hght.rxml. Accessed 31 Mar 2016

Dee DP, Uppala SM, Simmons AJ, Berrisford P, Poli P, Kobayashi S, Andrae U, Balmaseda MA, Balsamo G, Bauer P, Bechtold P, Beljaars ACM, van de Berg L, Bidlot J, Bormann N, Delsol C, Dragani R, Fuentes M, Geer AJ, Haimberger L, Healy SB, Hersbach H, H'olm EV, Isaksen L, Kallberg P, Kohler M, Matricardi M, McNally AP, Monge-Sanz BM, Morcrette JJ, Park BK, Peubey C, de Rosnay P, Tavolato C, Th'epaut JN, Vitart F (h) $06 \mathrm{FEB2013}$ 00UTC

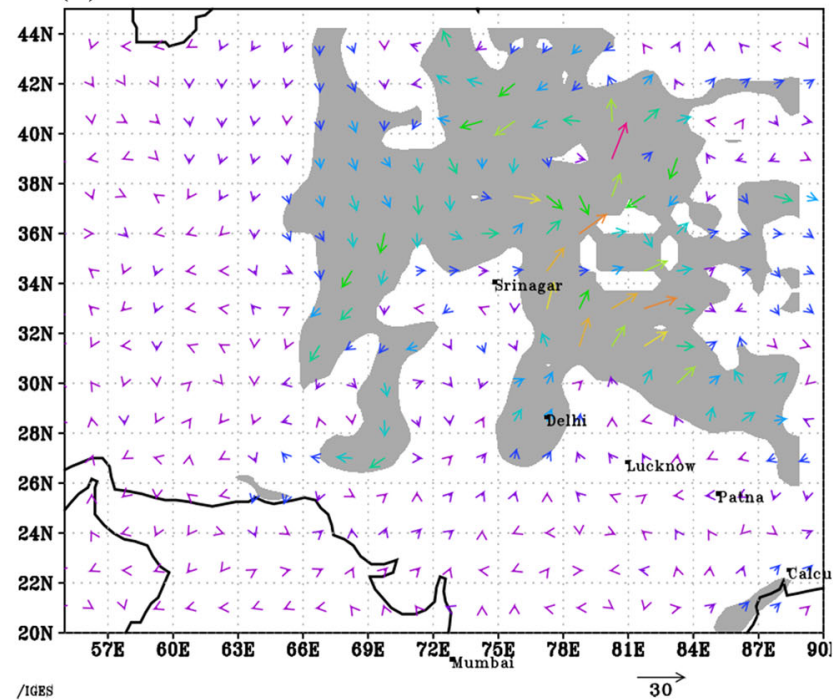

(2011) The ERAInterim reanalysis: configuration and performance of the data assimilation system. Q J R Meteorol Soc 137:553-597

Dimri AP, Chevuturi A (2014) Model sensitivity analysis study for western disturbances over the Himalayas. Meteorol Atmos Phys 123:155-180

Dimri AP, Mohanty UC (2009) Simulation of mesoscale features associated with intense western disturbances over western Himalayas. Meteorol Appl 16:289-308

Dimri AP, Mohanty UC, Mandal M (2004) Simulation of heavy precipitation associated with an intense western disturbance over Western Himalayas. Nat Hazards 31:499-552

Dudhia J (1989) Numerical study of convection observed during the winter monsoon experiment using a mesoscale two-dimensional model. J Atmos Sci 46:3077-3107

Dutta RK, Gupta MG (1967) Synoptic study of the formation and movement of western depression. Indian J Meteorol Geophys 18:45

Flaounas F, Bastin S, Janicot S (2010) Regional climate modelling of the 2006 West African monsoon: sensitivity to Cumulus and planetary boundary layer parameterisation using WRF. Clim Dyn 36:1083-1105

Gilmore MS, Straka JM, Rasmussen EN (2004) Precipitation uncertainty due to variations in precipitation particle parameters within a simple microphysics scheme. Mon Weather Rev 132:2610-2627

Hatwar HR, Yadav BP, Rao YVR (2005) Prediction of western disturbances and associated weather over Western Himalaya. Curr Sci 88:913-920

Hong SY, Lim JO (2006) The WRF single-moment 6-class microphysics scheme (WSM6). J Korean Meteor Soc 42:129-151

Hong SY, Dudhia J, Chen SH (2004) A revised approach to ice microphysical processes for the bulk parameterization of clouds and precipitation. Mon Weather Rev 132:103-120

Kain JS (2004) The Kain-Fritsch convective parameterization: an update. J Appl Meteor 43:170-181

Kim HJ, Wang B (2011) Sensitivity of the WRF model simulation of the East Asian summer monsoon in 1993 to shortwave radiation schemes and ozone absorption. Asia-Pacific J Atmos Sci 47:167-180 
Krieger JR, Zhang J, Atkinson DE, Zhang X, and Shulski MD (2009) Sensitivity of WRF model forecasts to different physical parameterizations in the Beaufort sea region. In: Proceedings of the 8th conference on coastal atmospheric and oceanic prediction and processes Phoenix, Ariz, USA

Lin Y, Colle BA (2011) A new bulk microphysical scheme that includes riming intensity and temperature-dependent ice characteristics. Mon Weather Rev 139:1013-1035

Marshall JS, Palmer WM (1948) The distribution of raindrops with size. J Meteor 5:165-166

Medha K, Sunitha DS, Kundale AP (2014) Weather in India WINTER SEASON (January-Februar 2013). MAUSAM 65:137-146

Mlawer EJ, Taubman SJ, Brown PD, Iacono MJ, Clough SA (1997) Radiative transfer for inhomogeneous atmosphere: RRTM, a validated correlated-k model for the long-wave. J Geophys Res 102:16663-16682

Morias DN, Jeffrey G et al (2007) Model evaluation guidelines for systematic quantification of accuracy in watershed simulations. Trans Asabe 50:885-900

Pai DS et al (2014) Development of a new high spatial resolution $(0.25 \times 0.25)$ long period daily gridded rainfall data set over India and its comparison with existing data sets over the region. Mausam 65:1-18

Pant GB, Rupa Kumar K (1997) Climate of Asia. Wiley, New York, pp 84-86

Paulson CA (1970) The mathematical representation of wind speed and temperature profiles in the unstable atmospheric surface layer. J Appl Meteor 9:857-861

Pisharoty P, Desai BN (1956) Western disturbances and Indian Weather. Indian J Meteorol Geophys 7:333-338

Raju PV, Potty J, Mohanty UC (2011) Sensitivity of physical parameterizations on prediction of tropical cyclone Nargis over the Bay of Bengal using WRF model. Meteorol Atmos Phys 113:125-137

Rao YP, Srinivasan V (1969) Discussion of typical synoptic weather situations: winter western disturbances and their associated features. Forecasting Manual, IMD. India, part III, 1.1

Rogers E, Black T, Ferrier B, Lin Y, Parrish D, Dimego G (2001) Changes to the NCEP Meso Eta Analysis and Forecast System: increase in resolution, new cloud microphysics, modified precipitation assimilation, modified 3DVAR analysis. NWS Tech Procedures Bull 488. http://www.emc.ncep.noaa.gov/ $\mathrm{mmb} / \mathrm{mmbpll} / \mathrm{eta} 12 \mathrm{tpb} /$

Singh MS (1979) Westerly upper air troughs and development of western disturbances over India. Mausam 30:405-414

Singh MS, Rao AVRK, Gupta SC (1981) Development and movement of a mid tropospheric cyclone in the westerlies over India. Mausam 32:45-50

Singh J, Knapp HV, Demissie M (2004) Hydrologic modeling of the Iroquois River watershed using HSPF and SWAT.ISWS CR 2004-08. Illinois State Water Survey, Champaign. http://www. sws.uiuc.edu/pubdoc/CR/ISWSCR2004-08.pdf. Accessed 8 Sept 2005

Skamarock WC, Klemp JB, Dudhia J, Gill DO, Barker DM, Huang XY, Wang W, Powers JG (2008) A description of the advanced research WRF version 3. NCAR Tech Notes- NCAR/TN$475+$ STR

Stull RB (2012) An introduction to boundary layer meteorology. Springer, New York

Wilks DS (2006) Statistical methods in the atmospheric sciences. Academic Press, Cambridge

William AG, James FB (2006) Comparison of impacts of WRF dynamic core, physics package, and initial conditions on warm season rainfall forecasts. Mon Weather Rev 134:2632-2641 